\title{
The Effects of Alcohol Use on Defiant Behavior among High School Students
}

\author{
Wesley A. Austin, Ph.D. \\ Department of Economics and Finance \\ University of Louisiana at Lafayette \\ Lafayette, Louisiana, U.S.
}

\begin{abstract}
Some controversy over the effects of alcohol use on societal outcomes (including educational achievement) has been noted in economics. While some issues have been addressed, important questions regarding human capital persist. This article explores whether drinking leads, in causal ways, to greater levels of unruly behaviors by high school students, and the possibility that any correlation between drinking and these behaviors might reflect unobservable factors? An instrumental variable model is estimated to investigate the impact of drinking on student actions such as gun carrying and fighting. Results indicate that alcohol use increases the incidence of these behaviors and effects remain stable across instrument specifications.
\end{abstract}

JEL Classifications: I12, I18, I21

Keywords: drinking, human capital, health, economics, behavior

\section{Introduction}

In several social science fields, there has long been fairly persistent concern about the possible harmful effects of alcohol consumption. A significant outcome of alcohol use is the potential lowering of human capital formation in the form of reduced grades and increased school dropout and absenteeism. This issue is particularly problematic during adolescence and early adulthood, in which decisions regarding high school completion and college attendance are first considered, and academic performance metrics that affect long-term educational and economic outcomes are initially observed. Excessive drinking has been associated with this age group despite its illegality until the age of 21 (Wechsler et al. 1994). For instance, recent data from the National Survey on Drug Use and Health (NSDUH) found 15 percent of high school students engaged in binge drinking (i.e. the consumption of five or more alcoholic beverages in one sitting, in the past month).

Several reasons might lead heavy drinking to reduce human capital accumulation. Drunkenness could interfere with class attendance and learning, and the time spent in activities where drinking occurs could substitute away from time allocated to studying. This could hurt academic performance in the short term, which might diminish the ability or incentive to continue schooling over the longer term. Risks stemming from intoxication, such as injury from accidents or fights, conflicts with parents or law enforcement, and a tarnished reputation with school authorities can also limit the capability of a student to attend school (Cook and Moore 1993). Alternatively, social interactions associated with drinking might improve academic achievement by providing a means of relieving stress (Williams et al. 2003).

The above studies, among others discussed below, has established a strong relationship between the regularity and intensity of drinking and human capital measures. But distinguishing whether this relationship is causal, such that, for example, increased alcohol consumption directly increases unruly school behaviors, or merely co relational, with changes in other variables simultaneously leading to drinking and defiant behaviors, is critical. Why is the potential impact of alcohol use on school behaviors relevant for the discipline of economics? Substantively, human capital obtained from schooling directly influences earning potential, and relationships to individual health have been established. Sanctions for defiant school behaviors often include suspension and/ or expulsion as well as possible legal sanctions - all of which diminish human capital accumulation. Further, variables such as years of completed schooling and quit rates are commonly examined education outcomes among broader literatures on human capital, given that they are easily measured and have a clear impact on future wages that labor economists have focused on estimating. 
This analysis, however, augments the literature by investigating effects on defiant school behaviors, i.e. fighting and gun carrying, which has not been widely studied despite potential effects on the acquisition of human capital. In addition, a very large dataset is utilized and potential endogeniety is accounted for given that the data is uniquely suited for the use of instrumental variables.

\section{Literature Survey}

The relationship between alcohol use and human capital attainment has been addressed by economists, but research on the topic has been fairly limited, with measures of drinking and educational outcomes, as well as conclusions, varying across studies. Comparatively early research produces evidence of a negative relationship, but either makes no attempt to econometrically investigate the potential endogeneity of drinking in education equations, or does so in a way that has since been criticized as inadequate. So it is unclear whether this negative correlation indeed represents declines in educational variables that are caused by drinking. Cook and Moore (1993), estimate IV models in which the effect of current alcohol use on post-secondary schooling is identified by the state excise tax on beer and an indicator for whether the student could legally drink based on the state's MLDA. Results from three separate specifications show that heavy drinking in $12^{\text {th }}$ grade decreased subsequent schooling. Dee and Evans (2003) call into question the causal effect interpretation of these results. They argue that the use of cross-state alcohol policy variation to identify the effects of drinking on other outcomes is potentially problematic because such variation might be correlated with unobservable factors that affect both alcohol use and educational attainment.

Two studies concerning the impact of drinking on the school-related behaviors have appeared in the economics literature and merit attention. Markowitz (2001) estimates effects of the number of days the respondent drank and binge drank over the prior 30 days on fighting and weapons carrying. Using a 2SLS procedure in which state level price measures, the beer tax, and an indicator of whether marijuana is decriminalized, serve as instruments, results show that the probability of having been in a physical fight during the previous year rose by about six percentage points with each day of drinking and 11 points with each binge drinking day. However, the IV methodology is subject to the same criticism as that of Cook and Moore (1993), in that state fixed effects were not included and thus cross-state price variation contributed to identification. Indeed, when census division indicators are added, both drinking measures become negative and insignificant in the fighting equations, but significantly positive in the gun carrying equation, while the F-statistics for the joint significance of the instruments fell from around four (significant though not particularly large) to below two and insignificant.

Roebuck et al. (2004) examines the likelihood of quitting school and truancy among a sample of 12-18 year olds who had not yet completed high school. A probit regression shows that those who consumed any alcohol over the previous year are 0.6 percent more likely to not be enrolled in school, but a negative binomial regression found no relationship between days truant and any past year drinking among those enrolled. Sen et al. (2009) finds only a spurious relation between drinking/ marijuana use and behaviors such as fighting, theft and running away from home among males; a more causal relation is found for theft and running away among females.

\section{Data}

In the United States, the National Survey on Drug Use and Health (NSDUH) is administered to approximately 55,000 civilian, non-institutionalized individuals age 12 and over, chosen so that the application of sample weights produces a nationally representative sample, with approximately equal numbers of respondents from the $12-17,18-25$ and 26 and over age groups. The analysis is conducted utilizing data from the 2007 and 2008 NSDUH

An important facet of the NSDUH data is that they are conducive for utilization in IV regression methodology where the causal effect of alcohol use on human capital can be estimated. Abundant information is collected on experiences related to alcohol consumption, including measures of parental disapproval of drinking, peer substance use, religiosity and the perceived risks involved in substance use. An assortment of variables are observed, therefore, that have the potential to serve as instruments for the proposed model, in the sense that they are very likely to be highly correlated with alcohol use but would not have any obvious reason to be otherwise associated with educational outcomes. 


\section{Research Method}

To establish causation, the primary methodological focus is whether drinking is properly specified as an exogenous variable with respect to school behavior or should instead be treated as endogenous.

Consider the following equations, in which drinking $(D)$ is a function of exogenous factors, and defiant behavior

$(B)$ is a function of some (but not all) of the same exogenous determinants as well as $D$,

(1) $D=\alpha_{0}+Z \alpha_{1}+X \alpha_{2}+\omega$,

(2) $B=\beta_{0}+\beta_{1} D+X \beta_{2}+\varepsilon$.

In the above equations, which apply to individual NSDUH respondents (with the corresponding observation-level subscript suppressed), vectors $X$ and $Z$ are sets of exogenous variables that affect both drinking and school behavior $(X)$, and drinking but not defiant behavior $(Z), \omega$ and $\varepsilon$ are error terms that encompass all factors influencing the corresponding dependent variable that are not explicitly controlled for on the right hand side of the equations, and the $\alpha$ 's and $\beta$ 's are parameters to be estimated. Econometrically, alcohol use is exogenous in equation 2 if it is uncorrelated with the error term $\varepsilon$. This condition holds, by definition, if none of the unobserved behavior determinants are related to drinking. If so, there is no need to estimate equation 1; a single equation regression method such as OLS will produce consistent estimates of the causal effect of drinking, $\beta_{1}$.

However, two sources of endogeneity could possibly lead to a nonzero correlation between alcohol use $(D)$ and the error term in equation (2). One is unobserved heterogeneity, which occurs should any of the unmeasured educational outcome determinants (e.g. school behavior) that are subsumed in the error term $\varepsilon$ be correlated with alcohol use; the resulting estimate of $\beta_{1}$ in equation (2) would suffer from omitted variable bias, which cannot be eliminated directly because the omitted variables are not recorded in the data. Disruptive events such as parental separation or divorce might simultaneously be responsible for greater alcohol consumption and increases in defiant school behaviors.

Such events are not observed and cannot be held constant in the regression and the positive correlation between drinking and defiant behaviors that they induce become embedded into the alcohol use coefficient, which is thus biased as an estimate of the causal drinking effect. Conversely, unmeasured ability or socioeconomic background could create a negative bias in the estimated drinking effect if higher ability individuals are better able to function normally after alcohol consumption, or students who have more money to spend on alcohol (and drink more) also enjoy greater academic success and are therefore less likely to exhibit defiant behaviors.

The other potential source of endogeneity is reverse causation. If alcohol use and educational events like school behavior are simultaneously determined, the outcome will not only be a function of drinking, as specified in equation 2 , but also will be a contributing factor to the decision regarding whether and how much alcohol to consume. In terms of equation 2 , shocks to the error term $\varepsilon$ that, by definition, influence educational outcomes will ultimately extend to drinking through the feedback effect of educational outcomes on alcohol consumption, thus creating a correlation between alcohol use and $\varepsilon$ that renders the estimate of the causal drinking effect $\beta_{1}$ inconsistent. To investigate the possibility that alcohol use is endogenous as an explanatory factor for school behavior, this study uses the method of instrumental variables (IV). To use IV, there must be at least one, preferably two or more, variables (i.e. instruments or IVs) that affect alcohol use but have no direct impact on school behaviors $(B)$. In the case of exactly one instrument $Z$, the IV method works by estimating the causal drinking effect $\beta_{1}$ as the ratio of the sample correlation between the instrument and achievement to the sample correlation between the instrument and alcohol use. Consider equation (3) below:

$$
\hat{\beta}_{1}=\operatorname{côrr}[Z, B] / \operatorname{côrr}[Z, D]
$$

Where the "^" symbolizes that the quantity is estimated from the data and the correlations are estimated while holding constant the vector $\boldsymbol{X}$ of explanatory factors. Because the instrument is exogenous and related to behavior only through drinking, the sample correlation between the instrument and behavior is purely a product of that between drinking and behavior. Thus, the sample correlation between the instrument and behavior merely needs to be standardized by that between the instrument and drinking in order to be used as an estimate for the causal effect of drinking on defiant behavior. Equation 3 makes transparent the two important conditions that the instrument vector $Z$ must satisfy in order for IV to produce consistent estimates of the causal drinking effect $\beta_{1}$ : First, the instruments must be highly correlated with alcohol use but not correlated with school behavior through 
any other mechanism besides drinking. If the correlation between the instruments and drinking is not statistically significant, the denominator in equation (3) is statistically equal to zero, thus rendering the expression for $\beta_{1}$ indeterminate. The strength of this correlation is judged from the F-statistic for the joint significance of $\alpha_{1}$ in equation 1.

Minimally, $\alpha_{1}$ should be significant at the 1 percent level; beyond this, Staiger and Stock [1997] advise a more stringent requirement that the associated F-statistic be at least 10. Second, if a direct correlation between the instruments and defiant behavior exists outside of the pathway from the instruments to drinking to behavior, the numerator in equation (3) includes variation that is not part of the relationship between drinking and behavior, and consequently the expression is no longer a consistent estimate of the causal effect of drinking. The reason multiple instruments are preferred is this over identifies equation 2 , which allows for specification tests to determine the empirical validity of excluding the instrument set $Z$ from equation (2).

One other methodological point merits attention. Although IV estimates are consistent if instrument strength and erogeneity conditions outlined above are satisfied, they are inefficient relative to OLS if it turns out that alcohol use is truly exogenous with respect to school behavior, in which case the OLS estimates can be interpreted as causal effects. Thus, it is desirable to econometrically test the null hypothesis that drinking is exogenous in the behavior equation. This is done using a Hausman (1978) test, which proffers that, if drinking and the error term are uncorrelated, IV and OLS estimates should differ only by sampling error. If the null hypothesis of exogeneity is rejected, OLS estimates are inconsistent and hence conclusions about causal effects should be based on IV estimates; failure to reject the null means that OLS estimates may be interpreted as causal effects and are preferable because of their smaller standard errors.

\subsection{Defiant School Behaviors}

The analysis is conducted utilizing a sample of currently enrolled high-school age students (14-17 years old) - a subsection of the NSDUH denoted Youth Experiences. All respondents are asked to report number of times they engaged in fighting and/ or gun carrying in the past 12 months with a possible response range of ( 0 or 1$)$; (2 or $3) ;(5$ or 6$) ;(9$ or 10$)$ or over 10 . In this study, a binary indicator is utilized and coded as ' 1 ' if the respondent did indeed engage in any fighting or gun carrying and ' 0 ' otherwise.

\subsection{Drinking Variables}

Among the varied alcohol use measures utilized are: the number of days the respondent drank in the past year (which is coded as ' 0 ' for nondrinkers and those that consumed no drinks in the previous year) and the number of drinks consumed in the previous month (which is coded as ' 0 ' for nondrinkers and those that consumed no drinks in the previous month). Binge drinking is defined as consuming five or more drinks on the same occasion on at least one day in the past thirty days.

The impact on school behavior from alcohol abuse or dependence in the past year is also examined. This is accomplished by an indicator in the NSDUH of whether respondents exhibited symptoms of alcohol abuse or dependence in the past year. This is retrospectively coded by SAMHSA based on responses to questions corresponding to criteria outlined in the fourth edition of the Diagnostic and Statistical Manual of Mental Disorders, the clinical standard for establishing drug abuse and dependence.

\subsection{Explanatory Variables}

Several variables from the NSDUH data are considered explanatory in the model: variables are included for whether the mother or father resides in the household and for whether parents assisted the student with homework always, sometimes or seldom in the past 12 months, with never as the omitted category. Also included are indicators for whether the student is currently attending the $9^{\text {th }}, 10^{\text {th }}, 11^{\text {th }}$, or $12^{\text {th }}$ grade (with $8^{\text {th }}$ as the omitted grade). Family income is measured in four categories: $\$ 20,000$ - $\$ 49,999 ; \$ 50,000-\$ 74,999 ; \$ 75,000$ or greater, with $\$ 0-\$ 19,999$ as the omitted category. Population density is represented by indicators for two categories: an MSA with one million persons or greater and an MSA of less than one million persons, with non-MSA areas as the omitted category. A measure for the number of times the student moved in the past year and a gender indicator are incorporated. For race, indicators are specified for African Americans, Native Americans, Asians, non-white Hispanics and multiracial, with Caucasians as the omitted category. Family size is measured using two variables: the number of members if the household has one to five members and an indicator for those with over five members. 


\subsection{Instrumental Variables}

Several NSDUH variables conceivably influence drinking without having direct effects on school behavior and are thus candidates to serve as instrumental variables. The specific variables utilized are: student is 16 years of age; peer use of alcohol; and perceived risk of bodily harm from alcohol use.

Age 16 could be connected to drinking as students of this age obtain drivers' licenses (and possibly fake IDs), possibly rebel against parents and attend more social functions where alcohol is consumed. Age 16 is not presumed to be directly connected to defiant behaviors except through the aforementioned "party" behavior. In other words, there is no a priori reason to believe that age 16 is directly connected to the proposed defiant behaviors.

Peer use information reflects respondents' perceptions regarding whether none, a few, most, or all students in the same grade at his or her school consume alcohol. For the peer use variable, a binary measure is defined to designate if the respondent feels that most or all schoolmates consume alcohol versus few or none. Potential endogeneity of the peer variable, stemming from a possible connection between one's own behavior and perceptions about the behavior of others, should be mitigated by the fact that the relevant questions cover all classmates rather than simply friends, who are presumably chosen by the respondent. Norton et al. (1998), Gaviria and Raphael (2001) and Kremer and Levy (2003) each find evidence that increased rates of drinking among peers raised the propensity to consume alcohol.

Risk aversion (i.e. risk of harm from drinking) could be linked to school behaviors in that more risk averse individuals are more likely to accumulate human capital (e.g., attend and graduate high school; maintain high grades)as "insurance" against having a low standard of living - with correct school behavior having a feedback effect on school attendance and grades. But in this model, risk aversion involves concerns about the direct consequences of consuming (for adolescents) an illegal substance. Therefore it is assumed to have no direct connection to deviant school behaviors. Some evidence shows that the risk associated with one variable is indeed different from risk associated with another - stated differently, risk aversion is not evenly spread among all aspects of human decisions (Heath and Tversky, 1991). Therefore, the risk associated with substance use may be different from, and quite possibly not correlated with, the risk associated with the consequences of defiant school behaviors. All instrumental variables undergo extensive testing in the following section.

\section{Results}

The causal effect drinking has on the probability of engaging in fighting and gun carrying is estimated using the three instrumental variables listed above. The over identification statistics aid in revealing whether the instrument set is exogenous with respect to these outcomes and an analysis is conducted to determine if some instrument sets are more plausibly exogenous than others. The main results of the IV analysis are also compared with parameter estimates obtained using OLS. While the discussion that follows concentrates on the effects of alcohol consumption and specification tests, appendix 1, for the binge drinking measure, shows the IV coefficients and marginal effect standard errors of all exogenous variables for the for the incidence of both behaviors.

Table 1 presents select summary statistics. The mean number of days drinks were consumed in the past year is 12.5 while the mean number of drinks consumed in the past month is 3.5. Approximately one-twelfth of high school students binge drink while about one-fifteenth are classified as alcohol dependent/ abusive. A vast majority of youths, 88 percent, report their parents' discourage drinking while the mean value of reported peer drinking is approximately 0.6. Family income is less than $\$ 20,000$ for 16 percent of respondents. About 90 percent of respondents live in an MSA, roughly equally split between MSAs with populations greater than and less than one million. Fathers are less likely to be present in the household than are mothers and the proportion of parents that help with homework is quite high. African Americans comprise about 14 percent of the sample while non-white Hispanics account for about 16 percent and Asians three percent. 
Table 1. Descriptive Statistics

$(\mathrm{n}=18,910)$

\begin{tabular}{|c|c|c|}
\hline Variable & Mean & $\begin{array}{l}\text { Standard } \\
\text { De viation }\end{array}$ \\
\hline Number of days drank-past year & 12.540 & 38.168 \\
\hline Number of drinks in previous month & 3.476 & 23.334 \\
\hline Binge drinking in the past 30 days & 0.078 & 0.269 \\
\hline Abuse/ Dependence on alcohol classification & 0.059 & 0.235 \\
\hline Respondent perceives risk of harm from drinking & 0.775 & 0.418 \\
\hline Respondent perceives peer use of alcohol & 0.607 & 0.488 \\
\hline Parents disapprove of alcohol & 0.886 & 0.320 \\
\hline Respondent engaged in fighting (past 12 months) & 0.126 & 0.332 \\
\hline Respondent carried a gun (past 12 months) & 0.038 & 0.192 \\
\hline Family income (less than $\$ 20,000)$ & 0.169 & 0.375 \\
\hline Family income $(\$ 20,000-\$ 49,999)$ & 0.331 & 0.471 \\
\hline Family income $(\$ 50,000-\$ 74,999)$ & 0.200 & 0.396 \\
\hline Family income $(\$ 75,000$ or more $)$ & 0.309 & 0.462 \\
\hline MSA segement with $1+$ million persons & 0.421 & 0.494 \\
\hline MSA segment of less than 1 million & 0.480 & 0.499 \\
\hline Age of student ( 14 years old) & 0.254 & 0.435 \\
\hline Age of student ( 15 years old) & 0.237 & 0.437 \\
\hline Age of student ( 16 years old) & 0.251 & 0.434 \\
\hline Age of student ( 17 years old) & 0.236 & 0.424 \\
\hline Mother in household & 0.907 & 0.290 \\
\hline Father in household & 0.714 & 0.451 \\
\hline Parents help with homework (always) & 0.539 & 0.498 \\
\hline Parents help with homework (sometimes) & 0.233 & 0.423 \\
\hline Parents help with homework (seldom) & 0.117 & 0.321 \\
\hline Grade in ( $8 \mathrm{th}$ grade) & 0.102 & 0.303 \\
\hline Grade in (9th grade) & 0.261 & 0.439 \\
\hline Grade in ( $10 t h$ grade) & 0.261 & 0.439 \\
\hline Grade in ( 11 th grade) & 0.237 & 0.424 \\
\hline Grade in ( 12 th grade) & 0.136 & 0.343 \\
\hline Race (Caucasian) & 0.640 & 0.421 \\
\hline Race (African American) & 0.144 & 0.351 \\
\hline Race (Native American) & 0.015 & 0.120 \\
\hline Race (Asian) & 0.033 & 0.178 \\
\hline Race (non-white Hispanic) & 0.168 & 0.374 \\
\hline Number in family & 3.239 & 1.577 \\
\hline Number in family $(>5)$ & 0.147 & 0.355 \\
\hline
\end{tabular}




\subsection{First Stage Regression Results}

Results from first stage regressions of the drinking measures on the instrumental variables are shown in table 2.

Table 2. First stage regression estimates for the behavior outcomes

$(\mathrm{n}=18,910)$

\begin{tabular}{lcccc}
\hline exogenous variables & $\begin{array}{c}\text { number of days } \\
\text { drank in past year }\end{array}$ & $\begin{array}{c}\text { number of drinks } \\
\text { in past month }\end{array}$ & Binge & \multicolumn{2}{c}{$\begin{array}{c}\text { Abuse/ Dependence } \\
\text { drinking }\end{array}$} & on alcohol \\
\hline Student is Age 16 & 1.451 & 0.398 & 0.003 & 0.006 \\
& $(0.689)$ & $(0.417)$ & $(0.005)$ & -0.083 \\
Risk of bodily harm from drinking & -10.818 & -5.023 & $(0.004)$ & -0.057 \\
& $(0.631)$ & $(0.385)$ & 0.069 & $(0.004)$ \\
Peer use of alcohol & 10.273 & 3.342 & $(0.003)$ & 0.051 \\
& $(0.547)$ & $(0.331)$ & 83.99 & $(0.003)$ \\
\hline F stat/ chi2-coefficient of joint significance & 55.27 & 34.86 & $(0.0000)$ & 40.80 \\
P-value of significance level & $(0.0000)$ & $(0.0000)$ & $(0.0000)$ \\
\hline
\end{tabular}

Being age 16 increases all alcohol use measures. The number of days drinking occurred in the past year is raised by approximately 1.5 days. The number of drinks consumed in the past month rises by roughly one-third, while the probability of binge drinking in the last 30 days increases by 0.003 . The likelihood of being categorized as abusive/ dependent on alcohol increases by roughly 0.01 .

For respondents who agree that there is moderate to great risk of harm from consuming 4-5 drinks about twice per week, the number of days that drinking occurred in the past year is lowered by approximately 10 days. The number of drinks consumed in the past month is reduced by five while the probability of binge drinking in the last 30 days falls by 0.08 percentage points, and the likelihood of being categorized as abusive/ dependent on alcohol falls by 0.06 percentage points. For respondents who report most or all their schoolmates use alcohol, the number of days drinking occurred in the past year rises by about ten days, the number of drinks consumed in the past month rises by approximately 3.5 , the probability of binge drinking in the last 30 days rises by 0.07 points, and the likelihood of being categorized as abusive/ dependent on alcohol increases by 0.05 points. The F-statistics and $\chi^{2}$ coefficients and associated p-values indicate that the instruments are jointly significant for all the drinking measures.

\subsection{The Effects of Drinking on Fighting}

Table 3,IV/ OLS estimates of drinking on the probability of fighting

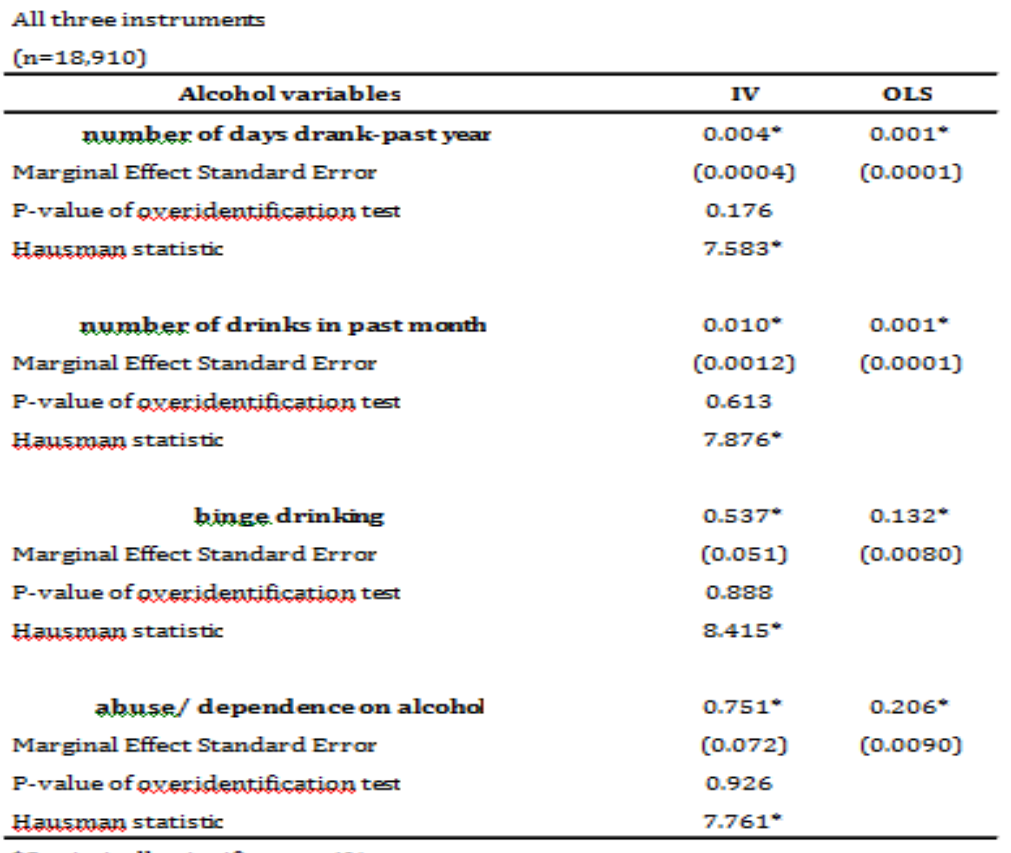

"Statistically significant at 1\% 
The findings in table 3 show that youth drinking leads to increases in the incidence of fighting in the past 12 months. An additional day increase in the number of past year drinking days increases the probability of fighting by 0.004 percentage points. If a student reports, for example, drinking 52 days in the previous year, the probability of fighting is elevated by 0.21 points compared to not drinking at all.

For each drink increase in the number of drinks consumed in the past month, the probability of fighting is raised by 0.01 . If the student consumes, on average, two alcoholic drinks per day in the past 30 days, relative to abstaining, the probability of engaging in fighting increases by 0.66 . For respondents that reported binge drinking in the previous 30 day period, there is an associated increase in the probability of fighting of 0.53 and for those categorized as abusive/ dependent on alcohol, the probability of fighting rises by 0.75.Overall, alcohol consumption serves to substantially increase the incidence of fighting.

For number of days drinking occurred in the past year, binging and abuse/ dependence on alcohol, the overidentification tests have associated p-values that offer evidence in support of the assumption of instrument exogeneity at the 10 percent level. Hausman tests indicate statistically significant differences between IV and OLS estimates for all drinking measures - the estimates differ by more than sampling error, indicating that drinking and the error term in equation 2 are in fact correlated and that drinking may be considered endogenous.

\subsection{Instrumental Variable Robustness and Fighting}

Table 5.IV/ OLS estimates of drinking on the probability of gun carrying

All three instruments

$(n=18,910]$

\begin{tabular}{|c|c|c|}
\hline Alcohol variables & IV & OLS \\
\hline number of days drank-past year & $0.002^{*}$ & $0.001^{*}$ \\
\hline Marginal Effect Standard Error & $(0.0003)$ & 0.0000 \\
\hline P-value of pxeridentification ter & 0.439 & \\
\hline Hausman statistic & $3.523^{\circ}$ & \\
\hline number of drinks in past month & $0.003^{\circ}$ & $0.001^{*}$ \\
\hline Marginal Effect Standard Error & $(0.0010)$ & 0.0000 \\
\hline P-value of pxeridentification ter & 0.067 & \\
\hline Hausman statistic & $3.800^{\circ}$ & \\
\hline binge drinking & $0.291^{*}$ & $0.054^{*}$ \\
\hline Marginal Effect Standard Error & $(0.057)$ & $(0.0052)$ \\
\hline P-value of pxeridentification ter & 0.236 & \\
\hline Hausman statistic & $4.201^{*}$ & \\
\hline abuse/ dependence on alcohol & $0.408^{4}$ & $0.085^{\circ}$ \\
\hline Marginal Effect Standard Error & $(0.083)$ & $(0.0058)$ \\
\hline P-value of pxeridentification ter & 0.153 & \\
\hline Hausman statistic & $3.901^{*}$ & \\
\hline
\end{tabular}

"Statistically significant at 1\% 
Table 4. IV estimates of drinking on the probability of fighting using IV pairs

$(\mathrm{n}=18,910)$

\begin{tabular}{|c|c|c|c|}
\hline & $\begin{array}{c}\text { age } 16 \\
\text { and alcohol risk }\end{array}$ & $\begin{array}{c}\text { alcohol risk and } \\
\text { peer drinking }\end{array}$ & $\begin{array}{c}\text { age } 16 \\
\text { and peer drinking }\end{array}$ \\
\hline \multicolumn{4}{|l|}{ Alcohol variables } \\
\hline number of days drank-past year & $0.004 *$ & $0.004 *$ & $0.004 *$ \\
\hline Marginal Effect Standard Error & $(0.0005)$ & $(0.0004)$ & $(0.0004)$ \\
\hline $\mathrm{P}$-value of overidentification test & 0.221 & 0.765 & 0.261 \\
\hline Hausman statistic & $5.017 *$ & $7.689 *$ & $5.162 *$ \\
\hline Coefficient (Standard Error) of omitted IV & $-0.004(0.007)$ & $-0.010(0.007)$ & $0.007(0.008)$ \\
\hline number of drinks in past month & $0.009 *$ & $0.010^{*}$ & $0.012 *$ \\
\hline Marginal Effect Standard Error & $(0.0014)$ & $(0.0013)$ & $(0.0020)$ \\
\hline$P$-value of overidentification test & 0.9775 & 0.618 & 0.996 \\
\hline Hausman statistic & $5.148^{*}$ & $7.868 *$ & $6.318^{*}$ \\
\hline Coefficient (Standard Error) of omitted IV & $0.007(0.007)$ & $-0.001(0.007)$ & $0.010(0.011)$ \\
\hline binge drinking & $0.544^{*}$ & $0.536^{*}$ & $0.531 *$ \\
\hline Marginal Effect Standard Error & $(0.0760)$ & $(0.0500)$ & $(0.0700)$ \\
\hline$P$-value of overidentification test & 0.896 & 0.994 & 0.893 \\
\hline Hausman statistic & $5.601 *$ & $8.407 *$ & $5.960 *$ \\
\hline Coefficient (Standard Error) of omitted IV & $-0.001(0.007)$ & $-0.003(0.006)$ & $0.001(0.008)$ \\
\hline abuse/dependence on alcohol & $0.781 *$ & $0.751 *$ & $0.724 *$ \\
\hline Marginal Effect Standard Error & $(0.1146)$ & $(0.0720)$ & $(0.0960)$ \\
\hline$P$-value of overidentification test & 0.995 & 0.928 & 0.966 \\
\hline Hausman statistic & $5.1657^{*}$ & $7.764 *$ & $5.754 *$ \\
\hline Coefficient (Standard Error) of omitted IV & $-0.002(0.007)$ & $-0.001(0.006)$ & $-0.003(0.008)$ \\
\hline
\end{tabular}

*Statistically significant at $1 \%$

To determine if there is any sensitivity in the main results attributable to changes in the instrument set, regressions are performed with varying pairs of instruments with results presented in table 4 . The instrument that is omitted from the IV combination is utilized as an explanatory variable and its coefficient and standard error is reported. All drinking measures have positive effects on fighting and the effects are noticeably similar to those in the main regression where all three instruments are employed. The over identification test results lend support to the exogeneity hypothesis for all IV pairs. Regardless of the instrument used, over identification results are consistent in support of exogeneity. In addition, Hausman tests indicate there are statistically significant differences between IV and OLS estimates in all specifications and the additional instrument not used to identify drinking is never significant in the fighting equation.

\subsection{The Effects of Drinking on Gun Carrying}

Table 5presents the IV regression estimates for the probability the respondent has carried a gun in the past 12 months. For all the drinking variables there are significant, positive effects on the probability of gun carrying Each day increase in the number of past year drinking days raises the probability of gun carrying by 0.002 , while the probability is raised by 0.003 for each extra drink consumed in the past month. For instance, if the respondent drinks 52 days in the past year, the probability of gun carrying is heightened by 0.10 . If 30 drinks are consumed by the student in the past month, the probability of gun carrying is raised by about 0.10 . For those that engaged in heavy drinking in the previous 30 day period, there is a significant positive effect on the probability gun carrying: the associated elevation in the probability is 0.29 for binge drinkers and 0.41 for those categorized as abusive/ dependent on alcohol. 
For the number of days drinking occurred in the past year, binging and abuse/ dependence on alcohol, the pvalues of the over identification tests afford support for the assumption of exogeneity except the monthly drinking variable where instrument exogeneity is rejected at the 5 percent level. Hausman tests indicate statistically significant differences between IV and OLS estimates for all drinking measures, again indicating that drinking and the error term in equation 2 are in fact correlated and that drinking may be considered endogenous.

\subsection{Instrument Robustness and Gun Carrying}

As with the fighting outcome, regressions are performed with varying pairs of instruments and table 6offers the results. The instrument that is omitted from the IV combination is utilized as an explanatory variable and its coefficient and standard error is reported. Again for all drinking variables, the effects on gun carrying are quite similar to those in the main regression save for when age 16 and peer drinking are used as an IV pair. For that pair, IV results are not significant and Hausman results fail to indicate statistical differences between IV and OLS estimates. For the other IV combinations, the over identification tests corroborate instrument erogeneity at the 10 percent level, while Hausman tests validate the hypothesis that IV and OLS estimates statistically differ. And the additional instrument not used to identify drinking is never significant in the gun carrying equation. For gun carrying, results are somewhat more sensitivity to instrument selection.

\subsection{General Comment on Instrument Robustness and OLS}

Overall, the robustness analyses offer some evidence to support the hypothesis that the instruments are exogenous. Over identification tests on differing pairs of instruments demonstrate that exogeniety is generally robust to any instrument set employed. And the effect of alcohol use on defiant behaviors is similar regardless of the utilized instrument set. Throughout the analyses, OLS parameter estimates, vis-à-vis IV, consistently underestimate the magnitude of the positive effects in the main specifications for fighting and gun carrying. This could be ascribed to the prospect that higher ability (i.e. higher achieving) students perform better academically even when they drink and these higher achievers are less likely to display defiant behaviors. In addition, higher income students (who spend more on alcohol and therefore drink more) may command more resources that can be channeled toward education and this in turn could serve to subdue bad behavior. It could also be that higher achieving students simply "like" school more, which in turn lowers the incidence bad behaviors. High achievers may have a higher opportunity cost with respect to misconduct, so defiant behavior is naturally less for these students, and the simple exhilaration of academic success could engender better school behavior. 


\section{Conclusions}

Table 6. IV estimates of drinking on the probability of gun carrying using IV pairs

$(\mathrm{n}=18,910)$

\begin{tabular}{|c|c|c|c|}
\hline & $\begin{array}{c}\text { age } 16 \\
\text { and alcohol risk }\end{array}$ & $\begin{array}{c}\text { alcohol risk and } \\
\text { peer drinking }\end{array}$ & $\begin{array}{l}\text { age } 16 \\
\text { and peer drinking }\end{array}$ \\
\hline \multicolumn{4}{|l|}{ Alcohol variables } \\
\hline number of days drank-past year & $0.002^{*}$ & $0.001^{*}$ & 0.002 \\
\hline Marginal Effect Standard Error & $(0.0003)$ & $(0.0003)$ & $(0.0020)$ \\
\hline P-value of overidentification test & 0.909 & 0.480 & 0.5648 \\
\hline Hausman statistic & $3.488^{*}$ & $3.441^{*}$ & 1.105 \\
\hline Coefficient (Standard Error) of omitted IV & $-0.001(0.000)$ & $0.001(0.003)$ & $0.018(0.036)$ \\
\hline number of drinks in past month & $0.004^{*}$ & $0.004^{*}$ & 0.013 \\
\hline Marginal Effect Standard Error & $(0.0008)$ & $(0.0009)$ & $(0.0158)$ \\
\hline P-value of overidentification test & 0.283 & 0.234 & 0.995 \\
\hline Hausman statistic & $3.843^{*}$ & $3.827^{*}$ & 0.900 \\
\hline Coefficient (Standard Error) of omitted IV & $-0.000(0.000)$ & $0.006(0.004)$ & $-0.142(0.126)$ \\
\hline binge drinking & $0.289^{*}$ & $0.293^{*}$ & 0.779 \\
\hline Marginal Effect Standard Error & $(0.0580)$ & $(0.0575)$ & $(0.7350)$ \\
\hline P-value of overidentification test & 0.355 & 0.572 & 0.508 \\
\hline Hausman statistic & $4.121^{*}$ & $3.463^{*}$ & 0.992 \\
\hline Coefficient (Standard Error) of omitted IV & $-0.000(0.000)$ & $0.005(0.003)$ & $-0.053(0.081)$ \\
\hline abuse/dependence on alcohol & $0.404^{*}$ & $0.417^{*}$ & $0.038^{*}$ \\
\hline Marginal Effect Standard Error & $(0.0846)$ & $(0.0845)$ & $(0.5280)$ \\
\hline P-value of overidentification test & 0.206 & 0.754 & 0.138 \\
\hline Hausman statistic & $3.812^{*}$ & $3.976^{*}$ & 0.082 \\
\hline Coefficient (Standard Error) of omitted IV & $-0.000(0.000)$ & $0.006(0.004)$ & $-0.028(0.041)$ \\
\hline
\end{tabular}

*Statistically significant at $1 \%$

This paper contributes to that literature by examining the effects of youth drinking on the probability a student engages in unruly and possibly dangerous behaviors among high school students, while accounting for unobserved endogeneity. For this study, the evidence reveals that when students use alcohol more frequently and intensely the probability of fighting and gun carrying is heightened, and, one may reason, the incidence of incurring associated penalties such as expulsion.

Throughout the analysis, over identification tests generally confirm instrument exogeneity and thus show that adolescent alcohol consumption should be treated as endogenous. Also, OLS regressions consistently underestimate the effects of alcohol use on the examined school behaviors. Although there is no direct analysis of the effectiveness of laws and other programs designed to curtail youth drinking, the conclusions support the premise that a reduction in adolescent alcohol use will enhance human capital formation by subduing defiant behavior. Minimum legal drinking ages, high school anti-drug programs and other policies aimed at lowering youth drinking may well be justified on these grounds. Although the instrumental variables prove to be empirically effective, further research should include continued exploration for reliable instruments to ensure that the relationship between drinking and academic outcomes is properly identified. A continued examination of the effectiveness of public policies that purport to reduce adolescent drinking would also prove valuable. 


\section{References}

Cassady, J. (2001). Self-reported GPA and SAT scores: A methodological note. Practical Assessment, Research \& Evaluation, 7(12).

Cook, P. J., Moore, M. J. (1993). Drinking and schooling. Journal of Health Economics, 12(4), 411-429.

Dee, T. S., Evans, W. N. (2003). Teen drinking and educational attainment: Evidence from two-sample instrumental variables estimates. Journal of Labor Economics, 21(1), 178-209.

Gaviria.A., Steven R. (2001). School-based peer effects and juvenile behavior. Review of Economics and Statistics, 83(2), 257-268.

Grant, B. F., Harford, T.C. \& Grigson, B.M. (1988). Stability of alcohol consumption among youth: a national longitudinal survey. Journal of Studies on Alcohol, 49(3), 253-260.

Harrison, L.,Hughes, A. (1997). The validity of self-reported drug use: Improving the accuracy of survey estimates. NIDA Research Monograph, 167, 1-16.

Hausman, J. A. (1978). Specification tests in econometrics. Econometrica, 46(6), 1251-1271.

Heath, C. \&Tversky, A. (1991). Preference and belief: Ambiguity and competence in choice under uncertainty. Journal of Risk and Uncertainty, 4, 5-28.

Kremer, M., Levy, D.M. (2003). Peer effects and alcohol use among college students. Journal of Economic Perspectives, 22(3): 189-206.

Markowitz, S. (2001). The role of alcohol and drug consumption in determining physical fights and weapon carrying by teenagers. Eastern Economic Journal, 27(4), 409-432.

Midanik, L. T. (1988). Validity of self-reported alcohol use: a literature review and assessment. British Journal of Addiction, 83, 1019-1029.

Norton, E. C., Lindrooth, R.C. \& Ennett, S.T. (1998).Controlling for the endogeneity of peer substance use on adolescent alcohol and tobacco use. Health Economics, 36 (7), 439-453.

Reinisch, E. J., Bell, R.M. \& Ellickson, P.L. (1991). How accurate are adolescent reports of drug use? Santa Monica, CA: Rand Corporation.

Roebuck, M., French, M.T. \& Dennis, M.L. (2004). Adolescent marijuana use and school attendance. Economics of Education Review, 23(2), 133-141.

Sen, B., Averett, S., Argys, L., \& Ress, D.I. (2009).The Effects of Substance Use on the Delinquent Behaviour of Adolescents. Applied Economics Letters, 16(17), 1721-1729.

Staiger, D., Stock, J.H. (1997). Instrumental variables regression with weak instruments. Econometrica, 65(3), 557-586.

Wechsler, H., Davenport, A., Dowdall, G., Moeykens, B., \& Castillo, S. (1994). Health and behavioral consequences of binge drinking: a national survey of students at 140 college campuses. Journal of the American Medical Association, 35(10), 1227-1239.

Williams, J., Powell, L.M. \& Wechsler, H. (2003). Does alcohol consumption reduce human capital accumulation? Evidence from the college alcohol study. Applied Economics, 35(10), 1227-1239. 